\title{
Evaluating the Effect of Cultural and Institutional Distance on the Proportion of B \& R Countries' Imports from China
}

\author{
Mohammad Reza Lotfollahi Ghaffari \\ School of International Trade and Economics, University of International Business and Economics, Beijing, China \\ Email: lotfi2005@gmail.com
}

How to cite this paper: Ghaffari, M. R. L. (2021). Evaluating the Effect of Cultural and Institutional Distance on the Proportion of B \& R Countries' Imports from China. Open Journal of Social Sciences, 9, 425-457. https://doi.org/10.4236/jss.2021.912028

Received: November 10, 2021

Accepted: December 28, 2021

Published: December 31, 2021

Copyright $\odot 2021$ by author(s) and Scientific Research Publishing Inc. This work is licensed under the Creative Commons Attribution International License (CC BY 4.0).

http://creativecommons.org/licenses/by/4.0/

Open Access

\begin{abstract}
The influence of cultural and institutional distance as intangible trade costs in the proportion of imports from China in the total import value of $B$ \& $R$ countries is investigated in this research. Panel data from 2008 to 2019 was used at the total product level between China and the other $51 \mathrm{~B} \& \mathrm{R}$ countries' import records. As the econometric method, an extended gravity model is used with the GEE estimation approach. Our findings show that institutional distance is more sensitive than cultural distance, hindering the proportion of China's exports to B \& $\mathrm{R}$ countries. Culture distance coefficient does not show high-level sensitivity to the proportion of import from China in the total import value of B \& R countries. It suggests that China's export is less affected by cultural distance. Moreover, the disparities in performance between European and Asian countries are investigated based on their proportion of imports from China in the total import value. As assumed, European countries' proportion of imports from China is smaller than that of Asian countries. The effect of institutional distance on European countries' proportion of imports from China is lower than that of Asian countries. The results of the generalized Wald's statistic test reveal that European and Asian countries differ not only in the constant term, but also in how the main variables affect the proportion of imports from China. This entails differences in both intercept terms and non-constant variable coefficients. In addition, a dummy variable BRI is represented for the year before or after the BRI announcement to shed light on whether China's export costs are depressed by it; our analysis reveals that the BRI announcement has implied an increase in the proportion of imports from China in the total import value of $B \& \mathrm{R}$ countries. Furthermore, we find that the BRI has a positive interaction term that reduces the institutional distance inhibiting effect on China's export to B \& R countries.
\end{abstract}




\section{Keywords}

Cultural and Institutional Distance, B \& R's Countries, Trade Costs and Proportion of Imports from China

\section{Introduction}

Many efforts have been done to calculate international trade costs in order to develop transaction cost measurement, as well as the geographical distance (Tinbergen, 1962) to institutional distance inhibitory effect (Liu, Lu, \& Wang, 2020). A lot of emphasis has been paid to direct measures of various trade costs. However, because tangible trade costs cannot fully modified international trade flows (Deardorff, 2004), the importance of intangible trade costs is recognized, and several researches have sought to convert intangible trade costs to tangible trade costs.

Intangible trade costs intervene in a firm's export process and lead to existing transaction costs; these costs have an uncertain effect on trade and can be identified but are difficult to compute or evaluate by firms. These include a loss of a firm's credit during a single export due to an exogenous factor, and the impact on the firm's future export records.

By applying international trade comparative advantage theory to firm-level impacts of tangible and intangible trade costs, such cultural and institutional distances have become more important. Numerous studies have examined the influence of institutional quality and culture distance on international trade costs, with some researchers having focused on both cultural and institutional distance (Tadesse, White, \& Zhongwen, 2017; Liu, Lu, \& Wang, 2020). However, there is no consensus among researchers on its significance.

Formal institutions determine the rules of transactions and the baseline environment for them. Formal institutions can also influence cultural norms and behavior; new government laws may influence cultural adaptability (Davis \& Williamson, 2016).

The informal institutions, known as norms of behaviors and customs, are components of a culture that varies in facts through time (North, 1995). When countries are more exposed to foreign trade, this aspect of culture may change more swiftly (Cyrus, 2012). Unlike other cultural characteristics such as languages, Informal Institutions can change rapidly over time. Institutional distance reflects the quality and compatibility of two countries' institutions and governess. On the other hand, the amount of empathy or indifference between the people of two countries is measured by cultural proximity or distance.

Discussions concerning BRI results and their countries' participation of global trade (30\% of global GDP) (Huang, 2016) compel us to consider them as our study samples. An economic framework for research with a membership of 65 nations that will grow to more than 120 in the future (http://www.chinagoabroad.com), be- 
sides evaluate the efficiency of initiatives to enhance export performance is a crucial element in achieving long-term economic growth in a country (Durmuşoğlu et al., 2012). Formalized paraphrase China, as the world's leading exporter in recent years, will account for 13\% of global trade value in 2020 (World Trade Statistical Review, 2021). According to the "One Belt One Road" Trade and Investment Development Report 2021 (http://www.mofcom.gov.cn/), B \& R countries import nearly $29 \%$ of their goods from China. Figure 1 illustrates boxplots representing the proportion of B \& R countries' imports from China from 2008 to 2019. The lowest points are the minimum proportion of imports from China each year, and the highest points are the maximum proportion of imports from China. The lowest point for 2012 is about 0.03 , indicating that China's lowest dominance in the B \& $\mathrm{R}$ import market was less than 3\%. Likewise, in 2012, China's maximum dominance in the B \& $\mathrm{R}$ import market was about 25.6 percent, rising to almost 29 percent in 2019. The lower and upper horizontal lines are represented in the first and third quartiles. For instance, in 2019, the lower horizontal line reflects the value 0.075 , which means that the proportion of imports of $25 \%$ of B \& R countries from China over their total imports is less than $7.5 \%$, and the proportion of imports of $75 \%$ of $B \& R$ countries from China

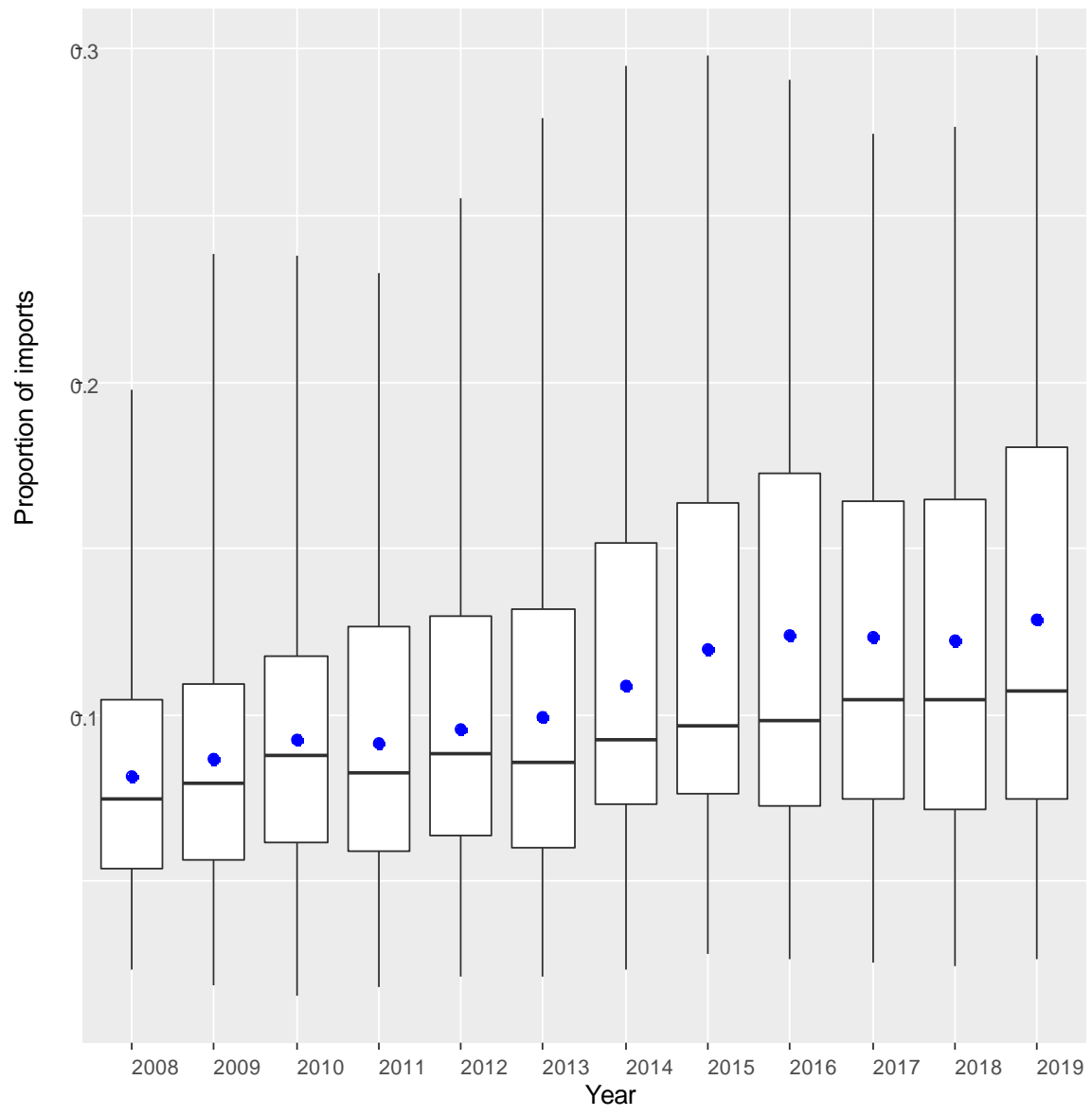

Figure 1. The proportion of imports from China in the total import value of B \& R's countries. 
over their total imports is at least equal to $7.5 \%$. The middle lines are drowned on the median; the median is near to 0.11 for 2017 and 2018 years, which implies that half of the B \& R countries accounted for less than $11 \%$ of the import market, and in $50 \%$ of $\mathrm{B} \& \mathrm{R}$ countries, more than $11 \%$ of the import market was held by China, which increased to more than $12 \%$ in 2019. Furthermore, the colored dots represent the average of the proportion of imports from China for B \& R countries. The mean is blue points; from 2008 to 2013, all of them are below $10 \%$, but starting in 2014 , they rose to over $10 \%$, and by 2019 , the mean was about $14 \%$ of the B \& R import market held by China. So our evaluating efficiency of BRI shows its announcement has a strong impact on the proportion of imports from China.

The overall outcome of experimental research indicates that the gravity model provides a good consistency. This explains why there is such a large volume of trade between countries. The extended gravity model proposed by (Anderson \& Van Wincoop, 2003) and followed by (Tadesse, White, \& Zhongwen, 2017) and (Liu, Lu, \& Wang, 2020) has also been used. Following Liu et al., we utilized nonlinear equations to model the proportion of imports from China in the total import value of B \& R countries using some covariates and adopted Generalized Estimating Equations (GEE) to estimate the proportion of imports from China in the total import value of B \& R countries by the intervention of cultural and institutional distance between China and its destinations.

Generalized Wald's statistics have been run to compare European and Asian countries to show that the European countries and the Asian countries differ not only in the constant term but also in how the main covariates affect the proportion of imports from China. One of our contributions is comparison before and after the BRI announcement statement by considering two regression models: first includes the main covariates, and the second also includes interactive terms between BRI and the main covariates to examine whether the effects of main covariates on the proportion of imports from China change before and after the BRI announcement or not?

Other contributions of this research are that in contrast to previous research procedures, it uses countries' self-reported import data rather than export data by the exporter; generally, this data is more accurate than export data since the exporter country's data are not necessarily the same as the importing country's data in one specific year as a result of re-exporting cases or some business tricks that happens for some reason. Moreover, the study evaluates the proportion of imports instead of import value. The proportions of imports from one country can be completely related to the variables considered in this study. Still, imports values are a function of other variables that are hidden but effective. Populations, for example, result in greater imports regardless of a country's economic level; a developed country frequently needs raw materials imports and occasionally imports less.

Also, using a neural network to predict missing cultural dimensions will help 
with feature research.

In Section 2, previous studies on the influence of cultural and institutional distance on bilateral trade will be reviewed. Section 3 explains the major variables in the gravity equation's theoretical foundation. Model building, variable selection, data sources, and the econometric model, as well as the Model estimator and the GEE method are covered in Section 4. Section 5 contains the estimation findings as well as a commentary. Finally, Section 6 concludes with some recommendations for policymakers to improve institutional quality while minimizing institutional distance and uncertainty.

\section{Literature Review}

\subsection{Transaction Costs}

Any element that causes a delay, a blockage, or unexpected or anticipated costs in the entire transaction, whether these costs are observable (tangible) or unobservable (intangible), can be characterized as transaction costs. Several researches have been carried out to demonstrate the positive and negative effects of various variables on trade volume. Tariffs between countries, geographical distance (Tinbergen, 1962), transportation costs, Landlock, customs clearance costs, port or airport handling charge, trade agreement, and exchange rate (Brada \& Méndez, 1988) are all tangible elements, while Intangible trade costs include common languages (Hummels, 2001), size of population and trade liberalization (Sheng \& Mullen, 2011), government size and colonial (Baranava, 2008), Immigration and transaction cost (Fan \& Zhang, 2016), (Haque et al, 2017), (Zhang Xiaoyi \& Liu Wen, 2019); (Lebesmuehlbacher \& Palmer 2020), and immigrants and cultural distances (White \& Tadesse 2008).

According to studies, landlock and economic differences, economic sanctions, colonies, difference in languages, and religious differences, have a significant negative impact on trade flow, whereas GDP, per capita output, trading partners, the size of the economy, trade agreements, and immigrants have a positive impact. Culture and institutions, also known as unobservable trade costs, are considered one of the most significant and influential components of trade between countries, in addition to the aforementioned elements.

(Linders, Burger, \& Van Oort, 2008) showed that both formal (tariffs, transportation costs, etc.) and informal (cultural and institutional distances) trade obstacles have remained influential. These tangible and intangible barriers are essential in understanding trade volume between countries. Trade costs are thought to be the golden key to unlocking the riddle of newly-opened macroeconomics (Obstfeld \& Rogoff, 2000); they can adequately explain policymakers' and economists' questions about why a country's volume of real trade is less than expected trade (De Jong \& Bogmans, 2011).

\subsection{Institutional Distances}

Institutions are the rules constructed to regulate human interaction. Formal 
constraints (rules, laws, and constitutions) are made up of informal constraints (norms of behavior, conventions, and self-imposed behavioral norms), as well as their enforcement features. They determine the incentive structure of society, and especially of economies when taken together (North, 2018). While the official mechanisms of enforcing institutions (laws, constitutions) may change slowly and in distinct ways, informal institutions may change more quickly and let changes in culture through time. Institutions are the rules of the game. Douglass emphasizes the significance of institutions in economic performance and considers economies' performance and efficiency to be influenced by their institutional nature. Furthermore, with increased market competition, property rights, contracts, and the Rule of law are among the most crucial institutions (Rodrik, Subramanian, \& Trebbi, 2004). The difference between the institutional profiles of two countries defines as institutional distance (Kostova, 1996).

(Kaufmann, Kraay, \& Zoido-Lobatón, 2002) definition and measurement of governance and governance institutions are based on six indicators is constructed for measuring institutions: Control of Corruption, Government Political Instability and Violence, Regulatory Quality, the Rule of Law, and Voice and Accountability and Government Effectiveness (World Governess Index, WGI), Section 3.2 and Table A1.

First time by (De Groot et al., 2004), Institutional distance entered the gravity model equation, and their effect was examined through six governance indices. According to this study, institutional distance negatively impacts trade flows and improves institutions' performance, and institutions' similarity was an influential trade factor and reduces transaction costs.

Following De. Groot, several studies have utilized these six measures to investigate the impact of institutions on trade. These studies are divided into two categories. The first is the Institutional quality index, which is a composite measure used to analyze the overall effect of institutional quality on trade, That will boost productivity, competitiveness, and trade value by better allocation of labor both domestically and internationally. Economic interaction laws and their effectiveness in the application are responsible for the best quality institutions (Borrmann, Busse, \& Neuhaus 2006). The second way is that the institutional distances between trading partners have an impact on bilateral trade levels (Linders et al., 2005) concluded that institutional distance hinders bilateral trade but the institutional quality of both the importer and exporter increases bilateral trade.

Institutional distances have a significant negative effect on trade, made the high cost to countries as one of the most significant trade barriers, and countries with more institutional similarities have more trade relations (Aljaz, 2012), (de Mendonça et al., 2014), and (Abedini, 2015).

(Kan, Lv, \& Luo, 2013), (Liu, Lu, \& Wang, 2020) investigated the impact of institutional distances on China's foreign trade flow. They demonstrated that institutional distances have a negative impact on China's foreign trade flow.

The negative effect of institutional distance could be seen as an institutional 
environment that reflects overall trade flow circumstances, and indeed, heterogeneous institutions are a causation for increased transaction costs.

\subsection{Cultural Distances}

Culture is defined as "the norms, values, and institutions that characterize a country's society" (Thompenaars \& Hampden-Turner, 1998), and the amount to which the shared norms and values in one country diverge from those in another" (Hofstede, 2001), (Kogut \& Singh, 1988).

If we consider a country's political, social, economic, and cultural systems, cultural changes take a long time, some aspects of which may take a thousand years (language, religion), even some socialists believe culture is unchangeable. Some researchers, such as (Cyrus, 2012), believe that culture can evolve; in particular, they believe that culture can change when a country's individualism is exposed to different beliefs and values such as trade. The critical question is, what aspects of culture can be altered as a result of cross-national trade? And in what way?

As the components of culture change at varying rates, culture can evolve at different rates. Culture imposes behavioral constraints that are distinct from those imposed by language and religion. In this field, the rate of change is different. For example, the rate of change in language is considerably slower than our daily activities, and the only path to the changeable part of culture is through conventions, unwritten norms, and rules that flow through society, and these rules are influenced by the institutions of a society. So, the informal institutions we know as norms of behavior conventions and behaviors are the component of a culture that evolves in facts throughout time.

This study will concentrate on what Douglass North refers to as "informal restraints," such as cultural norms of behavior. That is our concept of culture in terms of international trade and economics.

In general, academics looked into the impact of culture on international trade in three ways. To begin with, some scholars have argued that cultural distance allows countries to take the efficacy of comparative advantage, resulting in increased trade. These studies use the component of the culture that does not change or changes very slightly over time; the results demonstrate that cultural similarity is substantially correlated with trade flow (De Groot et al., 2004). A common language (Melitz, 2008), common religion (Guo, 2004), and (Hanousek \& Kočenda 2014), as well as the common colonizer (Bastos \& Silva, 2008) have a positive impact on trade. They will decrease transaction costs; these aspects of culture are referred to as cultural familiarity, and they do not change with time. Therefore, they have a positive effect on trade flow and promote it (Linders et al., 2005).

Second, some scholars have stated that cultural distance operates as a barrier to cross-border trade. It will grow transaction costs as a result of insufficient information, asymmetric information (Tadesse, White, \& Zhongwen, 2017); these 
studies measured the cultural distance index (Hofstede or WVS survey) which found that culture distance hindered trade flow and increased transaction costs and high uncertainty and less trust in contract (Cyrus, 2012).

Cultural barriers have more than merely a negative impact on bilateral trade. As cultural distances grow, some cultural features have a positive effect while some dimensions have a negative effect on trade flows. Some cultural characteristics such as power distance have a positive impact on it. The most significant influences on China's import and export trade are power distance and individuality, whereas uncertainty avoidance has the weakest impact (Tian \& Jiang, 2012). In the field of culture and culture products, a study by (Liu Xiaojuan and Zhangchen, 2020) indicated that the Hofstede dimension and the export of these cultural commodities have no significant impact.

Nonetheless, power distance has a negative impact on Chinese film and television production. Cultural distance inhibits the export of goods (Yu Kaili, 2015), but it has a greater positive effect on the trade of cultural products and cross-border tourism. This disparity stems primarily from the degree to which the cultural difference contributed to the rise in transaction costs, and the cultural difference caused the rise in consumers' cultural needs.

Third, the attraction of a specific country's culture to the inhabitants of another country can be a motivating factor that enhances the choice to import from that country. Language, ethnicity, social networks, religion, and social conventions, among other factors, can have a considerable impact on bilateral trade since they influence consumer preferences (Takayama, 2013). Cultural distance between trading partners reflects the appeal of one country's product to the consumers of the other (Dubois et al., 2013). It is argued that culture can influence overseas consumer demand through preference dispersion (Chang \& Lee, 2017).

Consumers, on the other hand, may have a home bias in domestic items as a result of their long-term consumption habits (Felbermayr et al., 2011), (Linders, Burger, \& Van Oort, 2008) suggest that "overlapping demand theory" holds that the more the similarity of consumer preferences between countries, the larger the overlapping of needs, and hence the greater the possibility of a trade.

In this research, the influence of culture distance will be analyzed using Hofstede's six culture dimensions, Section 3.1 and Table A2.

\subsection{Cultural Distances and Institutional Distances}

Despite the fact that numerous researchers have examined cultural distance and institutional distance separately, some studies have examined both these intangible trade costs in tandem. (Beugelsdijk et al., 2004) conducted empirical research on the relevance of various dimensions of cultural and institutional distance with former mentioned indices, They suggest nonlinear, inverted U-shape relation and demonstrated that the effect of cultural and institutional distance is not equivalent; institutional distance has an effect on export and FDI as low and 
high commitment modes, whereas cultural distance has an effect on only high commitment modes of FDI.

(Linders et al., 2005) observe positive effect of cultural distance and negative effect of institutional distance roles on bilateral trade. (Tabellini, 2010), (Chen Jianjun, 2018), and (Liu, Lu, \& Wang, 2020) conducted a study on the cultural and institutional distances between countries involved in international trade. (Liu, Lu, \& Wang, 2020) examined the impact of cultural and institutional distance on China's trade flows between B \& R and non-B \& R countries. Their findings indicated that cultural and institutional distance have a negative effect on China's bilateral trade flows; cultural distance has a stronger effect on China's trade with B \& R countries than institutional distance; cultural distance has a different effect on export to European and Asian countries than institutional distance; and institutional distance has the same effect on export to Europe and Asian countries.

According to (Roland \& Gorodnichenko, 2010), individualistic culture has a significant causal influence on economic growth. Individualism has a strong and quantitatively significant effect on long-run growth, even after accounting for different alternative hypotheses. Their research demonstrates the critical role of culture in long-run growth and discus about casual relation between culture and institutions.

(Li Jianan, 2016) showed the impact of institutions, culture, and geographic distance on China's foreign trade, indicating the importance of not only geographical distances between countries but also cultural and institutional distances. When these elements are taken into account as international trade transaction costs, China's worldwide market competitiveness will increase. Culture and institutions interact and evolve in a mutually reinforcing manner. As a result, the same institution at the same level may behave differently in various cultures. Additionally, culture may grow in a variety of ways depending on the sort of organization (Alesina \& Giuliano, 2015).

Because of the disparities in the samples used in the various studies, there is no coherent hypothesis concerning cultural and institutional distance performance on trade. These studies should be expanded further. Our research evaluates cultural and institutional distance before and after BRI, Europe or non-Europe B \& $\mathrm{R}$ countries, and contributes to existing literature.

\subsection{Literature Review Findings}

1) Tangible or intangible transaction cost can account for the gap between the real and estimated value of international trade.

2) There are three mechanisms via which cultural distance might affect trade; a positive, negative, and preference standpoint. Cultural distance in areas that are immutable or vary relatively little over time, such as language and religion, may enhance bilateral trade in the form of positive effects. The norms and behaviors referred to as informal institutions that may impede bilateral trade are the 
components of culture that change more swiftly over time and are primarily impacted by a country's institutions that may appear as negative effects form. Cultural differences between exporting and importing partners can also be a motivator for importing country consumers as well as a cause of demand.

3) Institutional quality can have a positive and efficient influence, while institutional distance can have a negative effect on a country's aim of boosting its trade volume. The possible interpretation is heterogeneous institutions have causality for increasing transaction costs.

4) The influence of cultural and institutional distance varies significantly between European and Asian countries; there is no general consensus, and conclusions should be drawn based on individual sample findings.

5) Cultural distance does not always have a negative impact and is not always sensitive in the case of China trade flows. This is especially true when there is an established institutional distance covariate. Nonetheless, there is no clear viewpoint in the literature, and additional research is required.

\section{Theoretical Framework of Former Gravity Mode}

The gravity model has frequently been utilized in international trade literature to investigate the factors that influence trade. This model commonly involves independent or mediating variables that might explain why international trade is easier or hard for people of two countries. (Isard, 1954) used the first model of gravity according to the General Theory of Gravity. Next, the logarithmic form of gravity equation was utilized by (Tinbergen, 1962), and then (Pöyhönen, 1963) found the standard pattern in international trade. They illustrated bilateral trade between two countries as a function of their respective economic sizes, $\mathrm{Yi}$ and Yj (GDP or GDPs), negatively correlated to geographic distance. Trade costs were not taken into consideration since the first gravity model lacked a theoretical foundation during a relatively long period from the late 1960s to late 1970; hence, a few researchers' attention was drawn to use this model. However, economists reconsidered it owing to its potency and validity in empirical research. Currently, researchers are attempting to improve the gravity equation using a theoretical model. It has widely been utilized and extended for observation and interpretation of unobservable variables such as culture, language, sharing a border, and Landlock since the 1970s; subsequently, the gravity equation has become a standard and public model in the field of international trade studies.

Based on the features of the expenditure system (Anderson, 1979) and (Jeffrey $\mathrm{H}$ Bergstrand, 2016) developed the simplest gravity model conceivable in the form of a linear expenditure system using a Cobb-Douglas function. In this research, each country producing a given product is considered to be fully specialized. (Anderson \& Van Wincoop, 2003) suggested a simple basic gravity equation model for both estimates and interpretation that can simply be applied using a theoretical fundamental gravity equation. 


\subsection{Measuring Cultural Distance}

Cross-cultural surveys such as Hofstede, Inglehart, and GLOBE are important indicators of culture. To quantify cultural distance between countries, the majority of academics employ two indicators. The World Value Surveys (WVS) index was produced by Inglehart et al. from seven waves of the World Value Surveys (1981-2021) and is not often utilized in international business research. The cultural dimension of (Hofstede, 2001) work is more frequently seen in studies of international trade. 1) Index of Power Distinction (PDI), 2) Index of Uncertainty Avoidance (UAI), 3) Index of Individualism (IDV), 4) Index of Masculinity-Femininity (MAS), 5) Index of Long-Term vs. Short-Term Orientation (LTOWVS), and 6) Index of Indulgence vs. Restraint (IVR), see Table A1.

Additionally, these dimensions are employed to evaluate the cultural distance. This is because the majority of the results were obtained using original data gathered based on Hofstede's multi-dimensional cultural distance. As a result, we also refer to the majority of researchers (Chen Jianjun, 2018), (Liu, Lu, \& Wang, 2020), who use six dimensions (Hofstede et al., 2010), employ a composite measure of cultural distance based on the (KSI) coefficient proposed by (Kogut \& Singh, 1988). Adjust the deviations to account for variations in the variances of the six dimensions and the arithmetically averaged, algebraically constructed index.

$$
C D_{j}^{k s i}=1 / 6 \sum_{d=1}^{6}\left(\frac{\left(I_{d j}-I_{d c}\right)^{2}}{v a r_{d}}\right)
$$

where $C D_{j}$ is the cultural difference of the $f^{\text {th }}$ country from China, $I_{d j}$ stands for the index of $d^{\text {th }}$ cultural dimensions and $f^{\text {th }}$ country, $I_{d C}$ stands for the index of $d^{\text {th }}$ China cultural dimensions, $V a r_{d}$ is the variance of the $d^{\text {th }}$ dimension.

\subsection{Institutional Distance Measuring Method}

A country's institutional quality compared to another country's is what is meant by institutional distance. Using (Kraay, Kaufmann, \& Mastruzzi, 2010) six dimensions of the institutional quality index, one can calculate the distance between institutions. This distance is calculated using Euclidean distance, as shown in Equation (2). The World Bank's Worldwide Governance Indicators (WGI) online database contains the country's scores on Kaufmann et al.'s six dimensions of governance quality, namely control of corruption (CC), Government effectiveness (GE), Political stabily and absence of violence/terrorism, the Rule of law (RQ), Regulatory quality (RL), voice, and accountability (VA). The six dimensions of institutional distance are described in detail in Table A2.

$$
\operatorname{INSTD}_{c j}^{\text {Euclid }}=\sqrt{\sum_{i=1}^{6}\left(I_{i j}-I_{i c}\right)^{2}}
$$

where $I N S T D_{c j}$ is the institutional distance of the $f^{\text {th }}$ country from China, $I_{i j}$ stands for the index of $i^{\text {th }}$ institutional index and $j^{\text {th }}$ country, $I_{i C}$ stands for the 
index of $i^{\text {th }}$ China institutional index.

\section{Model Construction, Variables Selection, and Data Sources}

\subsection{None-Linear Model and Estimating Approach}

Heteroscedasticity, which is often appeared in trade data, can cause the biasedness phenomena when running OLS estimation on a log-linearized model because the validity of this procedure strongly depends on the assumption of self-regulation of random error (error factor). Therefore, $\ln$ (random error) should be statistically independent of the other regressors, and also its mean should not depend on the regressors at this method (Silva, Tenreyro, \& Martí Ŕnez-Zarzoso, 2006). However, the variance of the error factor depends on other explanatory variables (GDP, CD, INSTD...) in the log-linearized model. On the other hand, by Jensen's inequality, one can easily find that Eln $(\mathrm{Y})$ is not equal with $\operatorname{lnE}(\mathrm{Y})$, so like some other researchers (Silva, Tenreyro, \& Martí Ŕnez-Zarzoso, 2006); (Beugelsdijk et al., 2004); (Liu, Lu, \& Wang 2020) we consider a nonlinear equation for modeling the proportion of imports from China in the total import value of $B \& R$ countries through some of the covariates, as the following form:

$$
\begin{aligned}
P_{i t}= & \exp \left\{\beta_{0}+\beta_{1} C D_{i}+\beta_{2} I N S T D_{i t}+\beta_{3} F T A_{i t}+\beta_{4} S H_{i t}\right. \\
& \left.+\beta_{5} L A N_{i t}+\beta_{6} E T H_{i}+\beta_{7} \ln G D P_{i t}+\beta_{7} \ln D I S T W_{i t}\right\} \varepsilon_{i t}
\end{aligned}
$$

Provided that

$$
E\left[\varepsilon_{i t} \mid C D_{i},{I N S T D_{i t}}, F^{\prime} A_{i t}, S H_{i}, L A N_{i}, E T H_{i t}, G D P_{i t}+D I S T W_{i}\right]=1
$$

which implies that

$$
\begin{aligned}
& E\left[\varepsilon_{i t} \mid C D_{i},{I N S T D_{i t}}, F T A_{i t}, S H_{i}, L A N_{i}, E T H_{i t}, G D P_{i t}+D_{S T T W}\right] \\
& =\exp \left\{\beta_{0}+\beta_{1} C D_{i}+\beta_{2}{I N S T D_{i t}}+\beta_{3} F_{T A}+\beta_{4} S H_{i t}+\beta_{5} L A N_{i t}\right. \\
& \left.+\beta_{6} E T H_{i}+\beta_{7} \ln G D P_{i t}+\beta_{8} \ln D I S T W_{i t}\right\}
\end{aligned}
$$

In the above equations, $P_{i t}$ denotes the proportion of imports from China in the total import value of country $i$ at year $t . C D_{i}$ denotes the cultural distance between China and the country $i$, which does not affect by time. INSTD $D_{i t}$ indicates the institutional distance between China and the country $i$ at time $t$. FTA denotes foreign trade agreement between China and B \& R countries. $\mathrm{SH}_{i}$ and $L A N_{i}$ are two dummy variables such that respectively take the value one if China and country $i$ share a common border and country $i$ is landlocked. Otherwise, they take the value zero. $G D P_{i t}$ is per capita GDP Of the country $i$ at time $t$. We use the GDP per capita of the partner countries instead of their GDP values serving as the purchasing power of the average consumer (Tadesse, White, \& Zhongwen 2017). DISTW $W_{i}$ denotes the weighted distance proposed by (CEPII 2021). And can be used to estimate the parameter Equation (3) conditioned on Equation (4). Note that the Poisson regression also works to nonnegative values, even if it is not a count variable. The PPML approach implies consistent but not necessarily efficient estimators for the target parameters $\beta$, since it 
ignores the serial correlation of import flows across the time. To obtain more efficient estimations, a generalized estimating equation (GEE) approach is considered based on Poisson PPML based on (Liang \& Zeger, 1986) idea. This approach uses some parametric structures for the serial correlation matrix, called the working correlation matrix. Despite the difference between the assumed working correlation matrix and the true correlation matrix, the GEE approach may imply more efficient estimators. There is some well-known working correlation matrix as the exchangeable correlation matrix, where correlations between any two periods are assumed to be the same as a constant: the unstructured correlation matrix which does not assume the default form, and the AR (1) structure which assumes the serial dependency at a time and all of the former time with a pre-determined form.

Here, we use the AR (1) structure. In this structure, $\operatorname{cor}\left(P_{i t}, P_{i t^{\prime}}\right)=\alpha^{\left|t-t^{\prime}\right|}$, for $0<\alpha<1$, i.e., when the distance between two times increases, the correlation between the proportions of the imports from China in two times decreases. Suppose that the proportion of imports from China and values of all of the covariates are available for the country $i$ in $T_{i}$ Years. Thus, we establish a $T_{i} \times T_{i}$ dimensional correlation working matrix of the form,

$$
R_{T_{i} \times T_{i}}=\left(\begin{array}{ccccc}
1 & a & a^{2} & \cdots & a^{T_{i}-1} \\
a & 1 & a & \cdots & a^{T_{i}-2} \\
a^{2} & a & 1 & \cdots & a^{T_{i}-3} \\
\vdots & \vdots & \vdots & \ddots & \vdots \\
a^{T_{i}-1} & a^{T_{i}-2} & a^{T_{i}-3} & \cdots & 1
\end{array}\right)
$$

Under these assumptions, the following objective function should be minimized in terms of the parameters to obtain the GEE estimators.

$$
\begin{aligned}
& \sum_{i}\left(P_{i}-E\left[P_{i} \mid C D_{i}, I N S T D_{i}, F_{T A}, S H_{i}, L_{A N}, E T H_{i}, G D P_{i}+D_{I S T W}\right]\right)^{\prime} R_{T_{i} \times T_{i}}^{-1} \\
& \times\left(P_{i}-E\left[P_{i} \mid C D_{i}, I N S T D_{i}, \text { FTA }_{i}, S H_{i}, L N_{i}, E T H_{i}, G D P_{i}+D_{I S T W}\right]\right)
\end{aligned}
$$

where $P_{i}$ denotes a $T_{i}$ by one vector that contains the proportion of imports from China in the total import value of country $i$ across the period 1 to $T_{i}$,

$$
E\left[P_{i} \mid C D_{i},{I N S T D_{i}}, F T A_{i}, S H_{i}, L N_{i}, E T H_{i}, G D P_{i}+D_{I S T W}\right]
$$

denotes a $T_{i}$ by one vector, which its components is obtained by substituting all of the covariates corresponding to the country $i$ in the equation

$$
\begin{aligned}
& \exp \left\{\beta_{0}+\beta_{1} C D_{i}+\beta_{2} I N S T D_{i t}+\beta_{3} F T A_{i t}+\beta_{4} S H_{i t}+\beta_{5} L A N_{i t}\right. \\
& \left.+\beta_{6} E T H_{i}+\beta_{7} \ln G D P_{i t}+\beta_{7} \ln D I S T W_{i t}\right\}
\end{aligned}
$$

for $t$ from 1 up to $T_{i}$. Also, $A^{\prime}$ means the transpose of a matrix $A$, and $R_{T_{i} \times T_{i}}^{-1}$ denotes the inverse matrix of the matrix $R_{T_{i} \times T_{i}}$. Under the mentioned assumptions, the GEE approach can be applied in R software.

\subsection{Data and Sample}

Cultural distance is computed based on Hofstede's six cultural dimensions. 
There are some missing values in the dimensions (LTOWVS) and (IVR) for some B \& R countries, including Bhutan, Kuwait, Qatar, and United Arab Emirates. In case with Siri Lanka and Syria, date on indulgence vs. restraint (IVR) is missing. One possible solution is to eliminate these counties from the study, but a better approach is to detect the missing values to keep these countries in the study. Here, an artificial neural network is employed for modeling the (LTOWVS) and (IVR) based on (PDI), (IDV), (MAS) and (UAI) to predict the missing values Appendix note 1. As mentioned before, we use The World Bank's Worldwide Governance Indicators (WGI) online database six dimensions for computing Institutional distance. GDP per capita data were collected from WDI in our sample. For FTA data, we referred to China's Ministry of Commerce. CEPII was utilized as a source for the weighted distance between countries, landlock, and ethnicity as dummy variables. For data sources, see Table A3.

Except for China that is the base country, we select the other $51 \mathrm{~B} \& \mathrm{R}$ countries as our sample, which have the possibility to collect data in our variable ranges for the study. there are missing data for countries Bhutan in years 2013-2019, Iran in the year 2019, Iraq in years 2008-2013, country Syria in years 2011-2019 due to unavailability of its per capita GDP, country Bhutan in years 2013-2019, Qatar in the year 2016, Sri Lanka in the year 2018 and the United Arab Emirates in years 2009-2011 due to unavailability of their imports from China or total import from the world. For list of countries and the proportion of China's export to these countries, refer to Table A4; we also provide summary statistics for our samples and variables in Table 1.

Table 1. Descriptive statistics.

\begin{tabular}{|c|c|c|c|c|c|c|}
\hline Variables & Obs & Mean & S.d & Median & Min & Max \\
\hline Import & 584 & $19,733,463.72$ & $31,617,603.9$ & $5,118,627.5$ & $10,059.00$ & $188,500,370.00$ \\
\hline GDP_per_Capita & 584 & $16,945.89$ & $16,891.81$ & $10,417.21$ & 958 & $85,076.14$ \\
\hline $\mathrm{CD}$ & 584 & 2.38 & 0.94 & 2.21 & 0.73 & 5.65 \\
\hline INSTD & 584 & 2.56 & 1.2 & 2.31 & 0.71 & 5.74 \\
\hline DISTW & 584 & 6460.54 & 2144.07 & 6927.43 & 1168.16 & $13,861.81$ \\
\hline FTA & 584 & 0.22 & 0.42 & 0.00 & 0.00 & 1.00 \\
\hline Share & 584 & 0.11 & 0.31 & 0.00 & 0.00 & 1.00 \\
\hline Landlock & 584 & 0.13 & 0.34 & 0.00 & 0.00 & 1.00 \\
\hline Ethnicity & 584 & 0.12 & 0.33 & 0.00 & 0.00 & 1.00 \\
\hline ln_GDP_per_Capita & 584 & 9.23 & 1.05 & 9.25 & 6.86 & 11.35 \\
\hline ln_DISTW & 584 & 8.7 & 0.43 & 8.84 & 7.06 & 9.54 \\
\hline Propotion_Import & 584 & 0.11 & 0.06 & 0.09 & 0.02 & 0.3 \\
\hline
\end{tabular}

Note: there are missing data for countries Bhutan in years 2013-2019, Iran in the year 2019, Iraq in years 2008-2013, country Syria in years 2011-2019 due to unavailability of its per capita GDP, country Bhutan in years 2013-2019, Qatar in the year 2016, Sri Lanka in the year 2018 and the United Arab Emirates in years 2009-2011 due to unavailability of their imports from China or total import from the world. 


\section{Results and Discussion}

\subsection{Estimations of Cultural and Institutional Distance Parameter}

We implemented the GEE approach for the dataset of the proportion of imports from China in the total import value of B \& R countries. The estimated value of parameter $\alpha$ in the correlation matrix is 0.8853 with the standard error of 0.02864 . To find a proper model, we first considered a model including all covariates. Step by step, we omitted the non-significant parameters from the model (highest p-value) to achieve a suitable and straightforward model. The results of this process are shown in Table 2. This Table presented the Poisson GEE estimates and their corresponding information in each step.

Based on data in Table 2, it is observed that the weighted geographical distance (DISTW) between a B \& R country and China is highly negative significant in all five Models. Some of the remaining covariates, including the institutional distance (INSTD), and the common border (SH), display a statistically significant negative and positive impact on the proportion of imports from China in all Models. The effect of the other covariates, including cultural distance (CD), (FTA), (LAN), (ETH), and GDP per capita GDP (ln GDP), is not statistically significant in models one to four. In model 5 , without ethnicity covariate, we can see (FTA) is significant. Generally, GDP per capita shows the significant positive sign in previous studies, reversely our evaluate shows is not significant that is because of increasing GDP per capita a country led to more engagement for trade, but it doesn't mean that the proportion of import from China will grow only, in other words, its proportion will not be changed, so it has no effect on the proportion of imports from China in the total import value of that country.

Overall, the statistical results confirm the evidence of negative effects of both weighted geographical distance that verifies earlier gravity model and institutional

Table 2. Estimations of cultural and institutional distance parameter on the proportion of imports from China in the total import value of B \& R countries.

\begin{tabular}{|c|c|c|c|c|c|c|c|c|c|c|c|c|c|c|c|c|c|c|c|c|}
\hline & & 1 & & & & & 2 & & & & 3 & & & & 4 & & & & 5 & \\
\hline 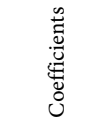 & 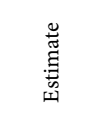 & 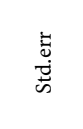 & $\frac{7}{3}$ & $\frac{\widehat{\overline{3}}}{\stackrel{\Lambda}{\Lambda}}$ & 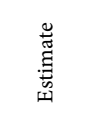 & $\begin{array}{l}\text { 苛 } \\
\text { 苟 }\end{array}$ & 营 & $\underset{\dot{a}}{\frac{\widehat{a}}{\wedge}}$ & 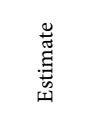 & 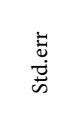 & $\frac{\vec{\pi}}{3}$ & 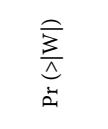 & 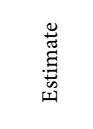 & $\begin{array}{l}\overrightarrow{0} \\
\vec{D} \\
\dot{D}\end{array}$ & $\frac{7}{3}$ & $\frac{\widehat{a}}{\stackrel{3}{\Lambda}}$ & 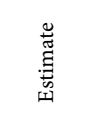 & 离 & $\begin{array}{l}\overrightarrow{7} \\
3 \\
3\end{array}$ & $\frac{\widehat{a}}{\stackrel{\hat{3}}{\Delta}}$ \\
\hline $\mathrm{CD}$ & -0.00518 & 0.06323 & 0.01 & 0.9348 & & & & & & & & & & & & & & & & \\
\hline ln_GDP & 0.02809 & 0.04043 & 0.48 & 0.4873 & 0.0274 & 0.0365 & 0.57 & 0.45209 & & & & & & & & & & & & \\
\hline Landlock & -0.12299 & 0.15491 & 0.63 & 0.4272 & -0.1218 & 0.1573 & 0.6 & 0.43871 & -0.1241 & 0.1591 & 0.61 & 0.435 & & & & & & & & \\
\hline Ethnicity & 0.09847 & 0.09936 & 0.98 & 0.3216 & 0.1005 & 0.097 & 1.07 & 0.3 & 0.1196 & 0.0915 & 1.71 & 0.191 & 0.1159 & 0.0911 & 1.62 & 0.203 & & & & \\
\hline INSTD & -0.06834 & 40.02841 & 5.79 & 0.0162 * & -0.0689 & 0.0287 & 5.76 & $0.01639 *$ & -0.0608 & 0.0282 & 4.65 & 0.031 * & -0.0604 & 0.0283 & 4.55 & 0.033 * & -0.0594 & 0.0278 & 4.59 & 0.03223 * \\
\hline FTA & 0.19757 & 0.15922 & 1.54 & 0.2147 & 0.1976 & 0.1588 & 1.55 & 0.21345 & 0.1548 & 0.1404 & 1.22 & 0.27 & 0.1927 & 0.1271 & 2.3 & 0.129 & 0.2522 & 0.1282 & 3.87 & 0.04913 * \\
\hline Share & 0.28808 & 0.11653 & 6.11 & 0.0134 * & 0.2902 & 0.1136 & 6.52 & 0.01065 * & 0.2589 & 0.1104 & 5.5 & 0.019 * & 0.2397 & 0.1242 & 3.73 & 0.054 . & 0.2221 & 0.1177 & 3.56 & 0.05912 \\
\hline Intercept & 1.7494 & 1.7494 & 1.37 & 0.2411 & 1.7683 & 1.4028 & 1.59 & 0.20748 & 2.2617 & 1.1634 & 3.78 & 0.052 . & 2.11 & 1.0975 & 3.7 & 0.055 . & 1.844 & 1.135 & 2.64 & 0.10423 \\
\hline
\end{tabular}

Note: Signif. codes: 0 “***» 0.001 “**” 0.01 “*” 0.05 “. ” 0.1 “” 1. 
distance between B \& R country and China that is addressed before by (Kan, Lv, \& Luo, 2013); (Liu, Lu, \& Wang, 2020), and others.

The negative effect of institutional distance in all models is considerable, it verifies institutional distances between countries can also be a high cost to countries as one of the most significant barriers to trade (Abedini, 2015), countries with more institutional similarities have more trade relations. (Aljaz, 2012) as institutional difference between home and host countries matters more than institutional quality of host country (Pattnaik, 2007) because of variance in subsidiary performance.

Model five give evidence of the positive impact of the foreign trade agreement and sharing a common border of a B \& R country with China on its proportion of imports from China. Even being in one framework allows all nations to converge; the findings reveal that FTA has an additional effect for countries that have already signed an agreement with China.

As we see, the culture distance coefficient does not show high-level sensitivity to the proportion of import from China in total import value, which verifies (Tadesse, White, \& Zhongwen, 2017) findings that China's trade is less affected by cultural factors distance than has been reported for other countries. It is apparently because two European and Asian countries have neutralized the effectiveness of cultural distance. More cultural differences between European nations and China may give China a comparative advantage in production and consumption while reducing the negative effect of cultural distance.

To evaluate the partial effect of a continuous covariate $x_{j}$ on the proportion of imports of $\mathrm{B} \& \mathrm{R}$ countries from China, $P$, we use the gamma coefficient for the variable $x_{j}$ is calculated as:

$$
\gamma_{x_{j}}=\frac{\partial P}{\partial x_{j}} \frac{s_{x_{j}}}{s_{P}}
$$

where, $\frac{\partial P}{\partial x_{j}}$ is the partial derivative of the proportion of imports with respect to covariate $x_{j}$, and $s_{x_{j}}$ and $s_{P}$ are the standard deviations of the observed values of the covariate $x_{j}$ And the observed values of the proportion of imports. We observed that the proper model is of the form

$$
\begin{aligned}
P= & \exp \{1.844-0.0594 * I N S T D+0.2522 * F T A \\
& +0.2221 * S H-0.4687 * \ln D I S T W\}
\end{aligned}
$$

The partial derivatives of $P$ in terms of INSTD and $\ln$ DISTW can be written as follows:

$$
\frac{\partial P}{\partial I N S T A N D}=-0.0594 P, \frac{\partial P}{\partial \ln \_ \text {DISTW }}=-0.4687 P
$$

It is clear that the partial derivatives depend on all of the covariates and all of the estimated parameters, which it arises from the nonlinearity of the considered model. Because the numerical values of the partial derivatives are needed to calculate the gamma coefficients, thus we use the average of the sample marginal 
effects (Kleiber \& Zeileis, 2008), by calculating a partial effect for each observation unit (where there are $T$ observations) and then averaging:

$$
\frac{\partial P}{\partial I N S T A N D}=-0.0594 \frac{\sum_{i=1}^{n} \sum_{t=1}^{T_{i}} P_{i t}}{\sum_{i=1}^{n} T_{i}}, \frac{\partial P}{\partial \ln \_D I S T W}=-0.4687 \frac{\sum_{i=1}^{n} \sum_{t=1}^{T_{i}} P_{i t}}{\sum_{i=1}^{n} T_{i}}
$$

where

$$
\begin{aligned}
P_{i t}= & \exp \left\{1.844-0.0594 * I N S T D_{i t}+0.2522 * F_{T A} A_{i t}\right. \\
& \left.+0.2221 * S H_{i}-0.4687 * \ln D_{I S T W_{i}}\right\}
\end{aligned}
$$

and $n$ is the number of countries understudying. By calculation of the average, we have

$$
\frac{\sum_{i=1}^{n} \sum_{t=1}^{T_{i}} P_{i t}}{\sum_{i=1}^{n} T_{i}}=0.106
$$

Also, we have $s_{\text {INSTD }}=1.2, s_{\text {In_DISTW }}=0.429$ and $s_{P}=0.0599$.

Therefore, the gamma coefficients for institutional distance and logarithm of weighted geographical distance are obtained as

$$
\gamma_{\text {INSTD }}=-0.127, \gamma_{\text {In_DISTW }}=-0.357 \text {. }
$$

We conclude that one standard deviation (1.2) increase in the institutional distance decreases the proportion of imports from China for B \& R countries by $12.7 \%(0.127)$ of the standard deviation of the proportion of imports from China (0.0599). Also, one standard deviation (0.429) increase in the logarithm of weighted geographical distance decreases the proportion of imports from China for B \& R countries by $35.7 \%$ ( 0.357$)$ of the standard deviation of the proportion of imports from China (0.0599). It appears that geographical distance continues to account for more variation in the proportion of Chinese imports in total import value of B \& R countries. It should be noted that the negative effect of institutional and cultural distance found in this study is consistent with (Linders et al., 2005).

\subsection{Comparison between European countries and Asian Countries}

To investigate the different performances between the proportion of imports from China for B \& R countries with Asian and European countries, a dummy variable EUROPE is introduced, which takes the value one for European countries and takes the value zero for Asian countries. For the sake of a consistent comparison between institutional distance and FTA on the proportion of imports from China for European and Asian countries, two interactive terms are created: (INSTD * EUROPE) and (FTA * EUROPE).

Table 3 presents the estimated parameters and reports the beta coefficients for (INSTD) and (ln_DISTW). The estimated coefficient on EUROPE is negative and significant, implying that in European countries, the lower proportion of imports is from China than Asian countries, which is consistent with the fact. This fact is obviously observed in Figure 2. 


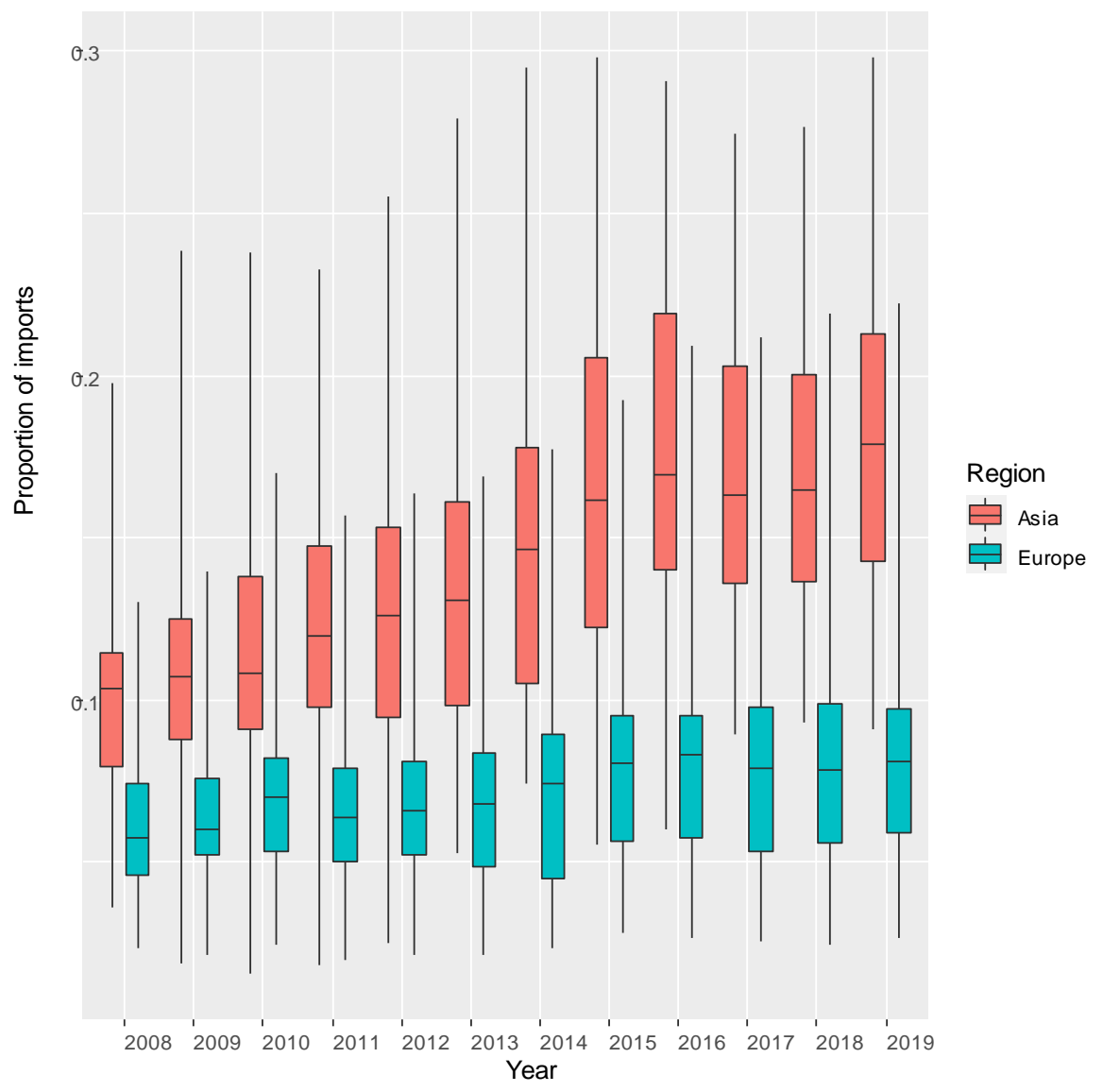

Figure 2. Comparison between The proportion of imports from China in the total import value of European countries and Asian countries.

Table 3. Comparison between European countries and Asian countries.

\begin{tabular}{ccccc}
\hline Coefficients & Estimate & Std. err & Wald & $\operatorname{Pr}(>|\mathrm{W}|)$ \\
\hline INSTD & -0.0314 & 0.0381 & 0.68 & 0.4107 \\
FTA & 0.1308 & 0.1327 & 0.97 & 0.32402 \\
Share & 0.1919 & 0.1531 & 1.57 & 0.2099 \\
ln_DISTW & -0.3458 & 0.1229 & 7.91 & 0.0049 ** \\
EUROPE & -0.385 & 0.2282 & 2.85 & 0.0916. \\
I (INST *EUROPE) & 0.0041 & 0.066 & 0.00 & 0.9505 \\
I (FTA * EUROPE) & 0.4694 & 0.1472 & 10.18 & $0.0014{ }^{* *}$ \\
Intercept & 0.9117 & 1.0747 & 0.72 & 0.3962 \\
\hline
\end{tabular}

Note: Signif. codes: 0 “***” 0.001 “**” 0.01 “*” 0.05 “.” 0.1 “” 1 .

The coefficient estimates on ln_DISTW is negative and statistically significant, which is an expected result. The coefficient estimates on the interaction term INSTD * EUROPE and FTA * EUROPE are positive, and the former is statistically significant. The latter implies that the effect of institutional distance on the proportion of imports from China for the European countries is lower than that for the Asian countries, that is might be because of heterogeneity of their gover- 
ness. and the former implies that the effect of FTA on the proportion of imports from China for the European countries is more than that for the Asian countries.

The descriptive statistics of the data are depicted in this Figure 2. In graphic mode, European countries are relatively near each other in different years from 2008 to 2015, with values ranging from 0.03 to 0.09 , but Asian countries shift from 2008 to 2019. Asia's countries are shifting away from 2014 (after the RBRI) and, particularly, 2015 and 2016, with a range of 0.8 to 0.22 . In 2016, the lowest point is about 0.025 , indicating that the lowest import of European countries was about 2.5 percent, indicating that the country with the fewest imports from China imported at least 2.5 percent of its products from China. The lower horizontal line is 0.06 , indicating that $25 \%$ of European countries import at least $6 \%$ of their products from China. The middle line is about 0.08 median, indicating that $50 \%$ of European countries import less than $8 \%$ of their products from China. Finally, the upper point is approximately 0.21 , meaning that most of Europe's imports came from a country that imported a least $21 \%$ of its products from China. The proportion of China's export to Asian countries is higher than European countries which is opposite of (Liu, Lu, \& Wang, 2020) findings.

\subsection{Generalized Wald's Statistic for Comparison of Europe and Asia}

Now, our goal is that are there differences of coefficients between the European countries and the Asian countries significant? To answer this question, we use the generalized Wald's statistic see (Hedeker \& Gibbons, 2006) to test the statistical significance of differences of coefficients between the European countries and the Asian countries. We consider the main covariates, the Europe variable, and interactions of all covariates with EUROPE. We test the joint null hypothesis that all coefficients on EUROPE and interactions of all covariates with Europe are zero. In this case, the Wald statistic is 37.99 (with $p$-value $=3.794 \mathrm{e}-07$ ), which follows the chi-squared distribution with 5 degrees of freedom. We strongly reject the null. This means that the European countries differ from the Asian countries in both intercept terms and the coefficients on non-constant variables. To further find out whether the difference is only due to the intercept term, we again test the joint null hypothesis that all coefficients on interactions of all covariates with EUROPE are zero. Wald's statistic is 37.45 (with $p$-value $=$ $1.452 \mathrm{e}-07$ ), which follows the chi-squared distribution with 4 degrees of freedom, which also suggests a strong rejection. This shows that the European countries and the Asian countries differ not only in the constant term but also differs in how the main variables affect the proportion of imports from China.

\subsection{BRI Effect}

To more rigorously discuss whether and to what extent the BRI affects the roles of the main covariates on the proportion of imports from China, we carried out a GEE regression. We defined a dummy variable BRI: whether the year is before or after the BRI announcement, which takes a value of one for the years after the 
BRI announcement and takes zero for the years before the BRI announcement. We consider two regression models: first includes the main covariates and BRI to examine the effect of BRI on the proportion of imports from China, and the second also includes interactive terms between BRI and the main covariates to examine whether the effects of main covariates on the proportion of imports from China change before and after the BRI announcement or not. The regression results have been reported in Table 4 . In model 1, we observe that the coefficients of (INSTD) and (ln_DISTW) are significantly negative. The coefficients of (FTA) and (SH) are significantly positive, which are compatible with the results obtained from Table 2. Also, in model 1, we see the beta coefficient is 0.0945 with $\mathrm{P}$-value $(1.9 \mathrm{e}-09)$. It shows that BRI strongly affects the proportion of imports from China. We conclude that the BRI announcement has been implied the increasing of the proportion of imports from China.

In model 2, the positive coefficient of (INSTD: BRI) shows BRI positive interaction term which decreases institutional distance inhibiting effect on the China's export to the B \& R countries and lead increase in the proportion of imports from China in the total import value.

We see that BRI statistically affects the roles of (FTA), (SH), and (ln_DISTW) on the proportion of imports. The negative coefficient of (ln_GDP_per_Capita: BRI) indicates the BRI statistically affects the function of (ln_GDP_per_Capita) on the proportion of imports from China for the B \& R countries. It implies that the decreasing in per capita GDP increases the proportion of imports from China after the BRI announcement.

The Figure 3 represents boxplots of the proportion of imports from China for B \& R countries before and after BRI announcement

Table 4. Estimations of BRI effect on the proportion of imports from China in the total import value of B \& R countries.

\begin{tabular}{|c|c|c|c|c|c|c|c|c|}
\hline \multirow{2}{*}{ Coefficients } & \multicolumn{4}{|c|}{ Model 2} & \multicolumn{4}{|c|}{ Model 1} \\
\hline & Estimate & Std. err & Wald & $\operatorname{Pr}(>|W|)$ & Estimate & Std. err & Wald & $\operatorname{Pr}(>|\mathrm{W}|)$ \\
\hline INSTD: BRI & 0.02123 & 0.01592 & 1.78 & 0.18236 & & & & \\
\hline FTA: BRI & 0.00112 & 0.0414 & 0.00 & 0.97839 & & & & \\
\hline Share: BRI & 0.02133 & 0.04696 & 0.21 & 0.64970 & & & & \\
\hline ln_GDP_per_Capita: BRI & -0.04570 & 0.01719 & 7.07 & $0.00784^{\star *}$ & & & & \\
\hline ln_DISTW: BRI & 0.00788 & 0.02758 & 0.08 & 0.77518 & & & & \\
\hline INST & -0.06059 & 0.02863 & 4.48 & $0.03432 *$ & -0.0472 & 0.0277 & 2.9 & 0.08845 \\
\hline FTA & 0.27133 & 0.1305 & 4.32 & $0.03760 *$ & 0.2752 & 0.138 & 3.98 & $0.04611^{*}$ \\
\hline Share & 0.24162 & 0.12714 & 3.61 & 0.05739 & 0.2626 & 0.1261 & 4.34 & $0.03729 *$ \\
\hline ln_GDP_per_Capita & 0.03690 & 0.03018 & 1.49 & 0.22158 & 0.0148 & 0.0342 & 0.19 & 0.66463 \\
\hline ln_DISTW & -0.45634 & 0.1284 & 12.63 & $0.00038^{* * *}$ & -0.4483 & 0.1316 & 11.61 & $0.00066^{* * *}$ \\
\hline BRI & 0.39079 & 0.34337 & 1.3 & 0.25508 & 0.0945 & 0.0157 & 36.03 & $1.9 \mathrm{e}-09^{\star \star *}$ \\
\hline Intercept & 1.34468 & 1.22377 & 1.21 & 0.27186 & 1.4389 & 1.2912 & 1.24 & 0.26511 \\
\hline
\end{tabular}

Note: Signif. codes: 0 “***” 0.001 “**” 0.01 “*” 0.05 “.” 0.1 “” 1 . 


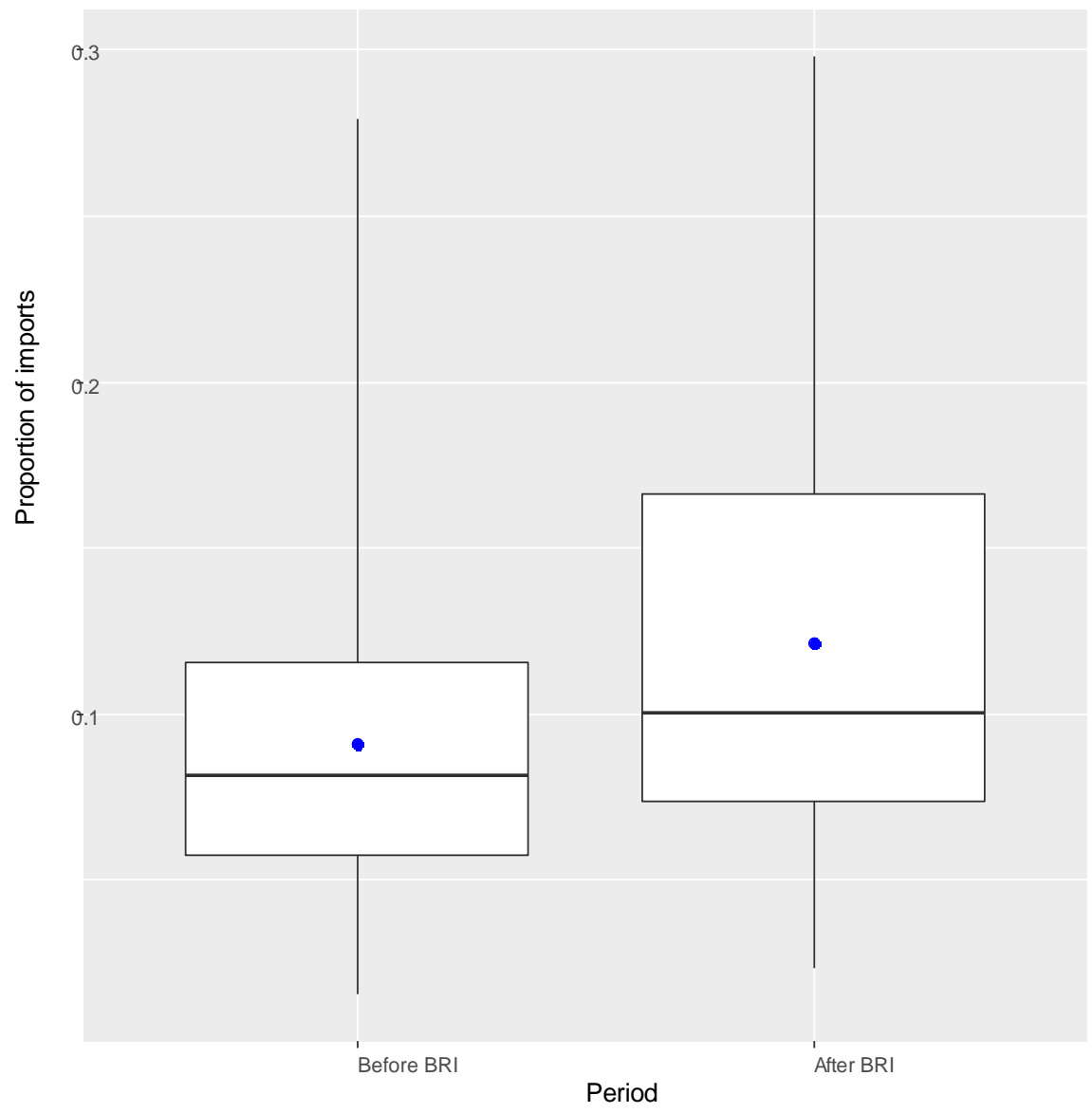

Figure 3. BRI announcement effects on the proportion of imports from China.

Before the BRI era, the centerline illustrates that $50 \%$ of nations imported less than $8 \%$ of their imports from China, but at least $10 \%$ of their imports came from China after the BRI. The upper horizontal line equals nearly 0.12 . That means 75 percent of countries imported at least 12 percent of their products from China before the BRI, but this 12 percent rose to 17 percent after the BRI, 5 percent increase. The median point of countries from China was approximately $9 \%$ before the BRI, but increased to $12 \%$ after the BRI. Intuitively, trade between countries is constantly rising. Still, the amazing and significant fact, which is yet another of our contributions, is that we are not talking about increasing trade volume but about the ratio of imports from China. According to prevailing opinion, this ratio should likewise represent a trend constantly. But we see that BRI has had a significant influence in increasing the proportion of imports from China.

\section{Conclusion and Discussions}

This paper is intended to evaluate the two intangible trade costs: cultural and institutional distance, which affect the proportion of imports from China in the total import value of B \& R's countries to draw out the costs of trade that reveal the secret of the mismatch between the actual amount of countries' exports and 
the value estimated by other trade patterns, using 2008-2019 panel data at total product level of 51 B \& R countries' import proportions records and employing Poisson GEE approach for evaluating the target covariates. The consistency and effectiveness of the Poisson GEE estimator provide robust results. In contrast to other researchers' procedures, choosing a data approach for analysis provides us with some contributions. First, we used self-reported import data from countries rather than export data from the exporter. The second approach is to analyze the proportion of imports rather than the value of imports. In fact, the proportions of imports from one country can be entirely related to the variables that we considered, but import values are a function of other, hidden but influential variables. Third, using a neural network to predict missing cultural dimensions will help with feature research. Fourth, study on the proportion of China's exports enables us to evaluate samples from before and after the BRI, yielding more effective results.

For evaluating the effect of institutional and cultural distance on the proportion of imports from China in the total import value of $B \& \mathrm{R}$ countries, we run several models, the impact of being European, the effect of BRI and their interactions on variables are discussed. It has greatly improved our understanding of the role of institutions for BRI countries.

Comparison of the effects of cultural distance and institutional distance shows Institutional distance has more hindrance effect on the proportion of imports from China in the total import value of B \& R's countries. It can be concluded that one standard deviation (1.2) increase in the institutional distance decreases the proportion of imports from China for B \& R countries by $12.7 \%$ of the standard deviation of the proportion of imports from China. The cultural distance coefficient does not show high-level sensitivity to the proportion of import from China in total import value. It might be because of existing both production comparative advantage for China and consumer preference effects for other countries to hindering cultural distance negative effect.

The results give proper evidence to support the difference between the proportion of imports from China for Asian and European B \& R countries. In this sense, the proportions of European countries are less than Asian countries, and its effect also is lower than Asian countries. General Wald's statistic examines how European countries and Asian countries differ not only in the constant term but also in how the main variables affect the proportion of imports from China. Furthermore, our evaluation shows the BRI announcement has implied the increasing of the proportion of imports from China.

Our findings include vital recommendations based on country-level estimate results.

First, The proportion of imports from China as most active trader in the world in the total import value of B \& R's countries is highly related to the differences in institutions, China policy maker must take massive care and engage both itself and other B \& R countries in improving the quality of institutions, with high institutional quality, economic actors can rely on property rights, con- 
tracts, or the rule of law. In that case, uncertainty on transaction costs will be reduced, which will led to establish new businesses, facilitate market operations, and help increase productivity, and provide a larger scale and use more efficient technologies. Increase competitiveness, and increase trade value. Inclusive institutions and good governance can be founding motivational systems are what (North \& Adriaan, 1991) calls the rules of the game which these Rules align self-efficacy with collective efficacy if the rules of the game are set in a way that enables healthy economic activity and has long-term benefits. In the long run, people will be assured that there is no corruption and their interests will be provided and life is predictable, And this predictable life becomes part of their mind map so, and that is why it shapes the changes on the part of a culture that is more alterable, these parts are called norms, value or appropriate behavior. Culture and institutions interact and evolve in a complementary way, with mutual feedback effects. They are complementarities and have interplay roles but, culture may evolve in differing ways depending on the type of institutions (Alesina \& Giuliano, 2015).

Second, When comparing European and Asian countries, Chinese exports to Europe are notably lower than Asian exports, even though the value of China's annual exports to a European country, for example, may be higher than that of one or two Asian countries. Data show that having foreign trade agreements with European countries is much more important for China than agreements with Asian countries. The European attraction term can partially compensate for the negative effects of institutional distance.

Third, our findings regarding the proportion of China's exports to $\mathrm{B} \& \mathrm{R}$ countries show that BRI as an economic framework has the inherent potential to reduce transaction costs due to the terms of its positive interaction, implying that China policymakers should better promote BRI as a global economic framework.

\section{Conflicts of Interest}

The author declares no conflicts of interest regarding the publication of this paper.

\section{References}

Abedini, J. (2015). Iceberg Trade Cost Measures: An Application to the OECD Area over 1988-2010. The International Trade Journal, 29, 115-141. https://doi.org/10.1080/08853908.2014.990071

Alesina, A., \& Giuliano, P. (2015). Culture and Institutions. Journal of Economic Literature, 53, 898-944. https://doi.org/10.1257/jel.53.4.898

Aljaz, K. (2012). Institutional Determinants of Bilateral Trade: Taking Another Look. Kiel Advanced Studies Working Papers No. 462.

Anderson, J. E. (1979). A Theoretical Foundation for the Gravity Equation. The American Economic Review, 69, 106-116.

Anderson, J. E., \& Van Wincoop, E. (2003). Gravity with Gravitas: A Solution to the Border Puzzle. American Economic Review, 93, 170-192.

https://doi.org/10.1257/000282803321455214 
Baranava, V. (2008). Essays on International Trade. All Dissertation, 209.

https://tigerprints.clemson.edu/all dissertations/209

Bastos, P., \& Silva, J. (2008). Cultural Links, Firm Heterogeneity and the Intensive and Extensive Margins of International Trade. SSRN, 23 p. https://doi.org/10.2139/ssrn.1373788

Bergstrand, J. H. (2016). The Gravity Equation in International Trade : Some Microeconomic Foundations and Empirical Evidence. The Review of Economics and Statistics, 67, 474-481. https://doi.org/10.2307/1925976

Beugelsdijk, S. et al. (2004). Cultural Distance, Institutional Distance and International Trade. European Regional Science Association.

Borrmann, A., Busse, M., \& Neuhaus, S. (2006). Institutional Quality and the Gains from Trade. Kyklos, 59, 345-368. https://doi.org/10.1111/j.1467-6435.2006.00336.x

Brada, J. C., \& Méndez, J. A. (1988). Exchange Rate Risk, Exchange Rate Regime and the Volume of International Trade. Kyklos, 41, 263-280.

https://doi.org/10.1111/j.1467-6435.1988.tb02309.x

Chang, P. L., \& Lee, I. H. (2017). Cultural Preferences in International Trade: Evidence from the Globalization of Korean Pop Culture. Research Collection School of Economics.

Chen, J. J. (2018). Research on Cultural Products Trade between China and Countries along the "Belt and Road" (Doctoral Dissertation, Zhongnan University of Economics and Law).

https://t.cnki.net/kcms/detail?v=hTfIJAoR2p YcmXlPd0H1PxNzLFPDFOMS44hTBU NWUI4S6BP71nzMtqwezNBWWKxOJneF3c6dkcKz9Lua6z0A8raE2TwqCmUlpio6-8 HB 3KoNe7J3Xh05hNiIukUhi\&uniplatform=NZKPT

Cyrus, T. L. (2012). Cultural Distance and Bilateral Trade. Global Economy Journal, 12, Article ID: 1850275. https://doi.org/10.1515/1524-5861.1895

Davis, L. S., \& Williamson, C. R. (2016). Culture and the Regulation of Entry. Journal of Comparative Economics, 44, 1055-1083. https://doi.org/10.1016/j.jce.2016.09.007

De Groot, H. L. F., Linders, G. J., Rietveld, P., \& Subramanian, U. (2004). The Institutional Determinants of Bilateral Trade Patterns. Kyklos, 57, 103-123.

https://doi.org/10.1111/j.0023-5962.2004.00245.x

De Jong, E., \& Bogmans, C. (2011). Does Corruption Discourage International Trade? European Journal of Political Economy, 27, 385-398. https://doi.org/10.1016/j.ejpoleco.2010.11.005

De Mendonça, T. G., Silva Lirio, V., José Braga, M., \& da Silva, O. M. (2014). Institutions and Bilateral Agricultural Trade. Procedia Economics and Finance, 14, 164-172. https://doi.org/10.1016/S2212-5671(14)00699-6

Deardorff, A. V. (2004). Local Comparative Advantage: Trade Costs and the Pattern of Trade. University of Michigan Research Seminar in International Economics Working Paper No. 500, 52 p. https://doi.org/10.2139/ssrn.510243

Dubois, P., Griffith, R., \& Nevo, A. (2013). Do Prices and Attributes Explain International Differences in Food Purchases? American Economic Review, 104, 832-867.

Durmuşoğlu, S. S. et al. (2012). The Effect of Government-Designed Export Promotion Service Use on Small and Medium-Sized Enterprise Goal Achievement: A Multidimensional View of Export Performance. Industrial Marketing Management, 41, 680-691. https://doi.org/10.1016/j.indmarman.2011.09.016

Fan, Z. B., \& Zhang, R. Y. (2016). International Migration Network and Trade Binary Margin: Evidence from China (pp. 5-16). https://doi.org/10.13509/j.cnki.ib.2016.05.001

Felbermayr, G. J. et al. (2011). Cultural Proximity and Trade. European Economic Re- 
view, 54, 279-293. https://doi.org/10.1016/j.euroecorev.2009.06.009

Guo, R. X. (2004). How Culture Influences Foreign Trade: Evidence from the US and China. The Journal of Socio-Economics, 33, 785-812.

https://doi.org/10.1016/j.socec.2004.09.045

Hanousek, J., \& Kočenda, E. (2014). Factors of Trade in Europe. Economic Systems, 38, 518-535. https://doi.org/10.1016/j.ecosys.2014.06.001

Haque, A. et al. (2017). FUSION-An Online Method for Multistream Classification. In International Conference on Information and Knowledge Management (pp. 919-928). https://doi.org/10.1145/3132847.3132886

Hedeker, D., \& Gibbons, R. D. (2006). Longitudinal Data Analysis (Vol. 451). John Wiley $\&$ Sons.

Hofstede, G. (2001). Culture's Consequences: Comparing Values, Behaviors, Institutions and Organizations across Nations. Sage Publications.

Hoftede, G., Hofstede, G. J., \& Minkov, M. (2010). Cultures and Organizations: Software of the Mind: Intercultural Cooperation and Its Importance for Survival. McGraw-Hill.

Huang, Y. P. (2016). Understanding China's Belt \& Road Initiative: Motivation, Framework and Assessment. China Economic Review, 40, 314-321.

https://doi.org/10.1016/j.chieco.2016.07.007

Hummels, D. (2001). Toward a Geography of Trade Costs. Purdue University.

Isard, W. (1954). Location Theory and Trade Theory: Short-Run Analysis. The Quarterly Journal of Economics, 68, 305-320. https://doi.org/10.2307/1884452

Kan, D. X., Lv, L. J., \& Luo, L. W. (2013). An Empirical Study on Institutional Distance and Foreign Trade Flows of Our Country-By Trade Gravity Model. Economic Survey, No. 2, 55-60.

Kaufmann, D., Kraay, A., \& Zoido-Lobatón, P. (2002). 2772 Governance Matters II: Updated Indicators for 2000-01. World Bank Publications.

Kleiber, C., \& Zeileis, A. (2008). Applied Econometrics with R. Springer Science \& Business Media. https://doi.org/10.1007/978-0-387-77318-6

Kogut, B., \& Singh, H. (1988). The Effect of National Culture on the Choice of Entry Mode. Journal of International Business Studies, 19, 411-432.

https://doi.org/10.1057/palgrave.jibs.8490394

Kostova, T. (1996). Success of the Transnational Transfer of Organizational Practices within Multinational Companies. University of Minnesota.

Kraay, A., Kaufmann, D., \& Mastruzzi, M. (2010). The Worldwide Governance Indicators: Methodology and Analytical Issues. The World Bank.

https://doi.org/10.1596/1813-9450-5430

Lebesmuehlbacher, T., \& Palmer, A. (2020). Immigration and Trade: Evidence from the 1920s Quota Acts. SSRN, 55 p. https://doi.org/10.2139/ssrn.3666464

Li, J. N. (2016). The Impact of the Triple Distance of System, Culture, and Geography on China's Foreign Trade. https://doi.org/10.14013/j.cnki.scxdh.2016.02.001

Liang, K. Y., \& Zeger, S. L. (1986). Longitudinal Data Analysis Using Generalized Linear Models. Biometrika, 73, 13-22. https://doi.org/10.1093/biomet/73.1.13

Linders, G. J., Burger, M. J., \& Van Oort, F. G. (2008). A Rather Empty World: The Many Faces of Distance and the Persistent Resistance to International Trade. Cambridge Journal of Regions, Economy and Society, 1, 439-458.

https://doi.org/10.1093/cjres/rsn019

Linders, G. J., Slangen, A. H. L., De Groot, H. L. F., \& Beugelsdijk, S. (2005). Cultural and 
Institutional Determinants of Bilateral Trade Flows. Tinbergen Institute Discussion Paper No. 05-074/3. https://doi.org/10.2139/ssrn.775504

Liu, A., Lu, C. C., \& Wang, Z. X. (2020). The Roles of Cultural and Institutional Distance in International Trade: Evidence from China's Trade with the Belt and Road Countries. China Economic Review, 61, Article ID: 101234.

https://doi.org/10.1016/j.chieco.2018.10.001

Liu, X. J., \& Zhang, C. (2020). An Evidence Study of the Impact of Cultural Distance on the Export of Chinese Film and Television Products in the Background of the "One Belt and One Road”. Shanghai Management Science, 42, 47-55.

Melitz, J. (2008). Language and Foreign Trade. European Economic Review, 52, 667-699. https://doi.org/10.1016/j.euroecorev.2007.05.002

North, D. C (2018). Institutional Change: A Framework of Analysis. In D. Braybrooke (Ed.), Social Rules (pp. 189-201). Routledge. https://doi.org/10.4324/9780429497278-13

North, D. C. (1995). The New Institutional Economics and Third World Development. Routledge. https://doi.org/10.4324/9780203444290-7

North, D. C., \& Adriaan, S. (1991). Institutions, Institutional Change and Economic Performance. The Economic Journal, 101, 1587-1589. https://doi.org/10.2307/2234910

Obstfeld, M., \& Rogoff, K. (2000). The Six Major Puzzles in International Macroeconomics: Is There a Common Cause? NBER Macroeconomics Annual, 15, 339-390. https://doi.org/10.1086/654423

Pattnaik, C. (2007). Do Institutional Quality and Institutional Distance Impact Subsidiary Performance? Academy of Management Annual Meeting Proceedings, 2007, 1-6. https://doi.org/10.5465/ambpp.2007.26508371

Pöyhönen, P. (1963). A Tentative Model for the Volume of Trade between Countries. Weltwirtschaftliches Archiv, 90, 93-100.

Rodrik, D., Subramanian, A., \& Trebbi, F., (2004). Institutions Rule: The Primacy of Institutions over Geography and Integration in Economic Development. Journal of Economic Growth, 9, 131-165. https://doi.org/10.1023/B:JOEG.0000031425.72248.85

Roland, G., \& Gorodnichenko, Y. (2010). Culture, Institutions and the Wealth of Nations. NBER Working Papers No. 16368.

Sheng, S. Y., \& Mullen, M. R. (2011). A Hybrid Model for Export Market Opportunity Analysis. International Marketing Review, 28, 163-182.

Silva, J. M. C. S., Tenreyro, S., \& MartíŔnez-Zarzoso, I. (2006). The Log of Gravity. The Review of Economics and Statistics, 88, 641-658. https://doi.org/10.1162/rest.88.4.641

Tabellini, G. (2010). Culture and Institutions: Economic Development in the Regions of Europe. Journal of the European Economic Association, 8, 677-716.

https://doi.org/10.1111/j.1542-4774.2010.tb00537.x

Tadesse, B., White, R., \& Huang, Z. W. (2017). Does China's Trade Defy Cultural Barriers? International Review of Applied Economics, 31, 398-428. https://doi.org/10.1080/02692171.2016.1257583

Takayama, P. B. (2013). Effects of the Concept of Cultural Distance on the International Trade of "Telenovelas". Journal of the Japan Society of Social Science on Latin America, 47, 61-78.

Thompenaars, F., \& Hampden-Turner, C. (1998). Riding the Waves of Culture: Understanding Cultural Diversity in Global Business. McGraw-Hill.

Tian, H., \& Jiang, C. C. (2012). Effect of National Cultural Distance on China's Foreign Trade: Data Analysis of 31 Countries and Regions' Trade Based on Gravity Model. Journal of International Trade, 3. https://10.13510/j.cnki.jit.2012.03.015 
Tinbergen, J. (1962). Shaping the World Economy; Suggestions for an International Economic Policy. Books (Jan Tinbergen). Twentieth Century Fund.

http://hdl.handle.net/1765/16826

White, R., \& Tadesse, B. (2008). Cultural Distance and the US Immigrant-Trade Link. The World Economy, 31, 1078-1096. https://doi.org/10.1111/j.1467-9701.2008.01115.x

World Trade Statistical Review (2021).

https://www.wto.org/english/res e/statis e/wts2021 e/wts21 toc e.htm

Yu, K. L., Yao, L. M., \& Xiao, X. (2015). An Empirical Study on the Impact of Cultural Closeness on Bilateral Cross-border Tourism: Taking China as an Example. Journal of Zhejiang University of Technology (Social Science), 14, 391-397, 458.

Zhang, X. Y., \& Liu, W. (2019). The Impact of China's Overseas Immigration Network on the Export Trade of Countries along the Belt and Road. Shandong Social Sciences, No. 6, 100-105. 


\section{Appendix Tables}

Table A1. Description in institutional measurement.

Six dimensions of the institutional quality index that are constructed based on Kaufmann et al.'s (2010)

1) Control of corruption expresses the degree to which public power is exercised for private gain.

2) Government effectiveness refers to the degree to which the government could formulate, implement and commit good

3) Political stability and absence of violence/terrorism reflect the likelihood of political instability.

4) The rule of law measures the degree to which citizens have confidence in and abide by society's rules.

5) Regulatory quality shows the quality of regulating policy formulation and implementation.

6) Voice and accountability reflects the degree to which the citizens could participate in selecting and monitoring their.

Table A2. Description in the measurement of cultural dimensions.

Six dimentions cultur distance base on Hofstede (2010)

1) Power distance index: The index measures the degree of inequality that exists in a society.

2) Uncertainty avoidance index: The index measures the extent to which a society feels threatened by uncertain or ambiguous situations.

3) Individualism index: The index measure the extent to which a society is individualistic. Individualism refers to a loosely knit social framework in a society where people are supposed to take care of themselves and their immediate families. The other end of the spectrum would be collectivism that occurs when there is a tight social framework in which people distinguish between in-groups and out-groups; they expect their in-groups (relatives, clans, organizations) to look after them in exchange for absolute loyalty.

4) Masculinity index (Achievement vs. Relationship): The index measures the extent to which the dominant values are assertiveness, money, and things (achievement), not caring for others, or quality of life. The other end of the spectrum would be femininity (relationship).

5) Long term orientation v.s. short term normative orientation implies the degree to which a society prioritizes the present

6) Indulgence v.s. Restraint refers to the degree to which a society allows free gratification of enjoying life and having fun rather than regulates it by strict norms.

Table A3. Counties included in the sample with relative import proportions*.

\begin{tabular}{cccc}
\hline & Region & Country & Mean value of Import (Pro) $)^{* *}$ \\
\hline 1 & Europe & Albania & 7.55 \\
2 & Asia & Armenia & 10.68 \\
\hline
\end{tabular}




\section{Continued}

\begin{tabular}{|c|c|c|c|}
\hline 3 & Asia & Azerbaijan & 7.82 \\
\hline 4 & Europe & Belarus & 5.93 \\
\hline 5 & Europe & Belgium & 2.90 \\
\hline 6 & Asia & Bhutan & 2.18 \\
\hline 7 & Europe & Bosnia and Herzegovina & 6.10 \\
\hline 8 & Europe & Bulgaria & 3.70 \\
\hline 9 & Europe & Croatia & 4.63 \\
\hline 10 & Europe & Czech Republic & 12.11 \\
\hline 11 & Europe & Estonia & 7.39 \\
\hline 12 & Europe & France & 8.42 \\
\hline 13 & Asia & Georgia & 7.61 \\
\hline 14 & Europe & Germany & 9.17 \\
\hline 15 & Europe & Greece & 5.74 \\
\hline 16 & Europe & Hungary & 5.69 \\
\hline 17 & Asia & India & 13.15 \\
\hline 18 & Asia & Indonesia & 18.42 \\
\hline 19 & Asia & Iran, Islamic Rep. & 18.43 \\
\hline 20 & Asia & Iraq & 17.58 \\
\hline 21 & Europe & Italy & 7.05 \\
\hline 22 & Asia & Japan & 22.63 \\
\hline 23 & Asia & Jordan & 11.87 \\
\hline 24 & Asia & Kazakhstan & 15.58 \\
\hline 25 & Asia & Kuwait & 14.51 \\
\hline 26 & Europe & Latvia & 2.81 \\
\hline 27 & Europe & Lithuania & 2.54 \\
\hline 28 & Europe & Macedonia & 5.64 \\
\hline 29 & Europe & Malaysia & 16.70 \\
\hline 30 & Europe & Moldova & 8.84 \\
\hline 31 & Europe & Montenegro & 7.62 \\
\hline 32 & Europe & Netherlands & 8.62 \\
\hline 33 & Asia & Pakistan & 19.37 \\
\hline 34 & Asia & Philippines & 14.13 \\
\hline 35 & Europe & Poland & 10.39 \\
\hline 36 & Asia & Qatar & 10.08 \\
\hline 37 & Europe & Romania & 4.65 \\
\hline
\end{tabular}




\section{Continued}

\begin{tabular}{lccc}
\hline 38 & Europe & Russian Federation & 17.96 \\
39 & Asia & Saudi Arabia & 13.87 \\
40 & Europe & Serbia & 7.86 \\
41 & Asia & Singapore & 12.06 \\
42 & Europe & Slovak Republic & 6.90 \\
43 & Europe & Slovenia & 5.64 \\
44 & Asia & South Korea & 18.35 \\
45 & Asia & Sri Lanka & 15.35 \\
46 & Asia & Syria & 13.60 \\
47 & Asia & Thailand & 16.70 \\
48 & Asia & Turkey & 9.76 \\
49 & Europe & Ukraine & 9.94 \\
50 & Asia & United Arab Emirates & 11.00 \\
51 & Asia & Vietnam & 26.42 \\
\hline
\end{tabular}

*Source of data: http://www.chinagoabroad.com. ${ }^{*}$ The proportion of imports from China in the total import value of countries, years (2008 to 2019).

Table A4. Variable's data and sources.

\begin{tabular}{cl}
\hline Variable & \multicolumn{1}{c}{ Data sources } \\
\hline P (pro) & $\begin{array}{l}\text { The proportion of imports from China in the total import } \\
\text { value of BRI countries base Total product } \\
\text { level/measured in thousand of US Dollar } \\
\text { https://www.trademap.org/ }\end{array}$ \\
Culculation based on data from Hofstede Insights. \\
http://geert-hofstede.com
\end{tabular}




\section{Appendix Note}

Calculation of missing Long term orientation v.s. Short term normative orientation (LTOWVS), and Indulgence v.s. Restraint (IVR) dimensions:

To keep these countries in our study. Here, we apply an artificial neural network for modeling the (LTOWVS), and (IVR) based on (LTOWVS) and (IVR) based on (PDI), (IDV), (MAS) and (UAI) to predict the missing values.

For this purpose, we first used a neural network with 2 layers, the first one with 4 neurons and the second one with 7 neurons; the entries are predictive factors: pdi, idv, mas, and uai, the output is (LTOWVS), and logistic activation function of the form

$$
f(x)=\left(1+\mathrm{e}^{-x}\right)^{-1} .
$$

Figure A1 illustrates the corresponding neural network.

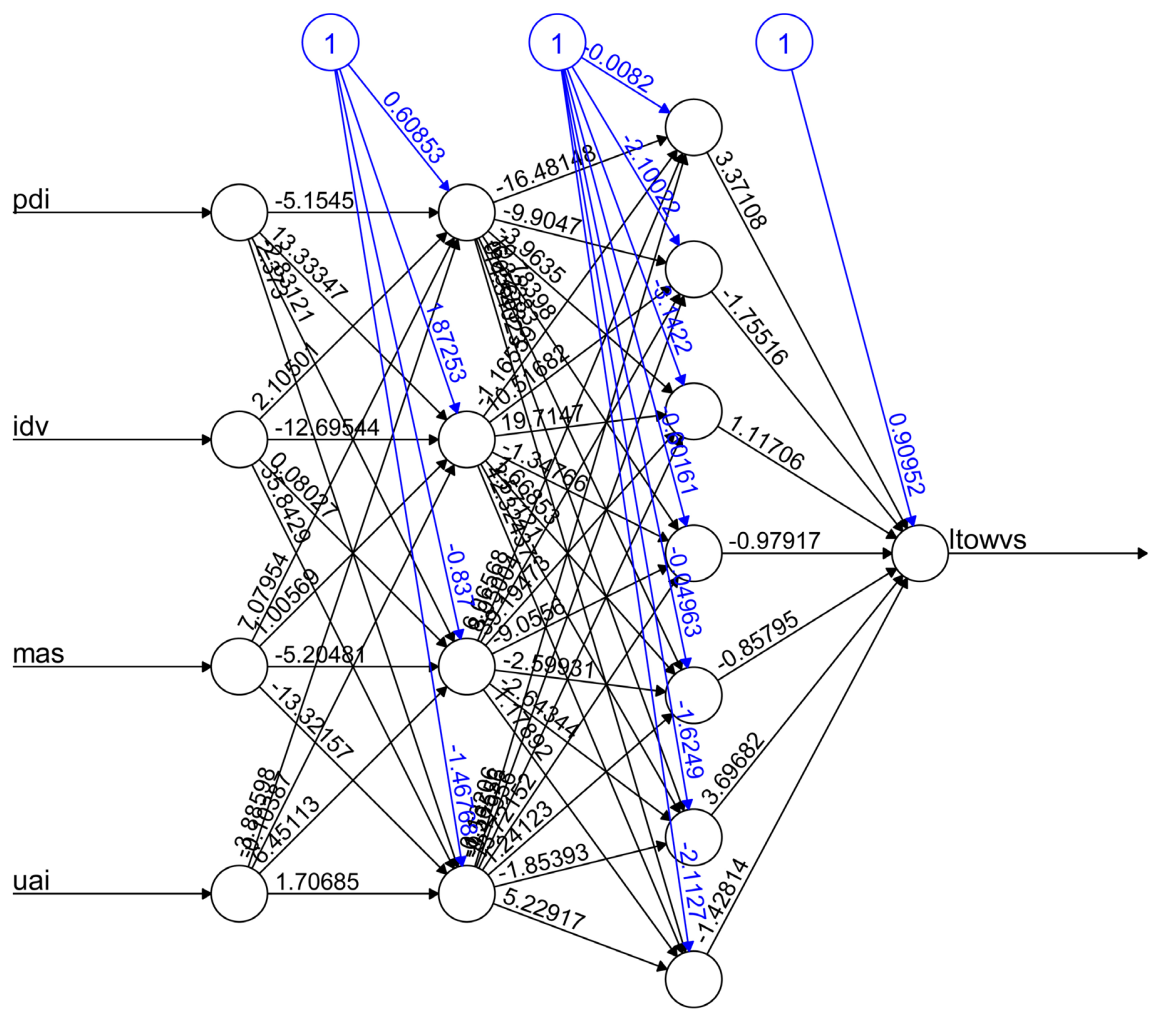

Error: 0.217476 Steps: 755

Figure A1. Neural network for modelling long-term vs. short-term orientation based on the predictive factors.

To observe the performance of the used neural network, we plotted the scatter plot of the predicted values of ltowvs versus the real ltowvs. Figure A2 illustrates this plot. Obviously, we see that the points are close to the line with angle 45 degrees.

Similarly, we utilized a neural network with 2 layers, the first one with 5 neurons and the second one with 3 neurons, for modelling (IVR) based on the pre- 
dictive factors: (PDI), (IDV), (MAS) and (UAI), and with hyperbolic tangent activation function of the form $f(x)=\frac{\mathrm{e}^{x}-\mathrm{e}^{-x}}{\mathrm{e}^{x}+\mathrm{e}^{-x}}$.

Long-Term Vs. Short Term

Orientation

by neural network

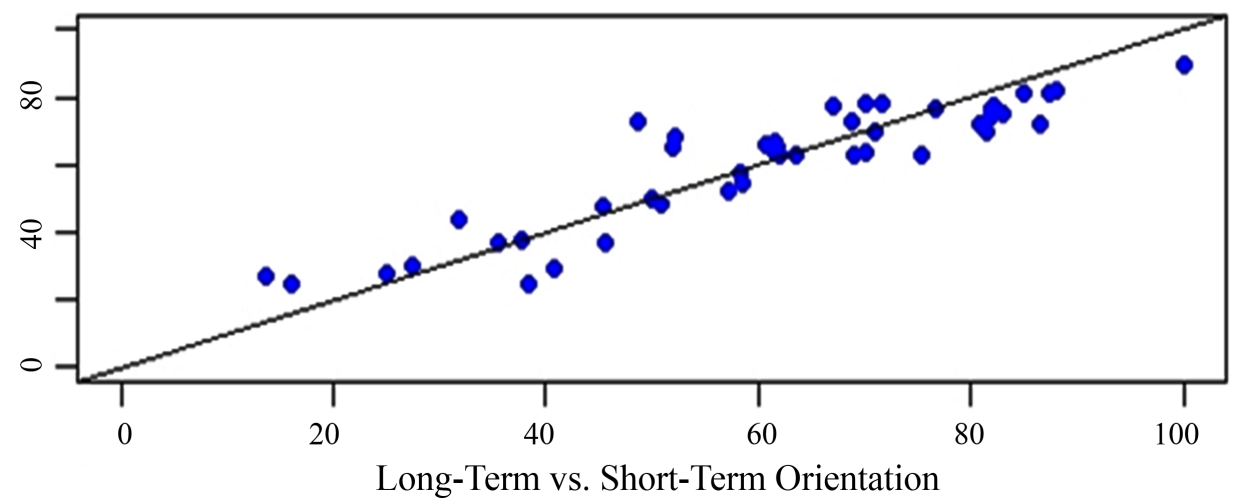

Figure A2. Scatter plot of the predicted values of (LTOWVS) versus the real (LTOWVS).

Figure A3 illustrates the corresponding neural network.

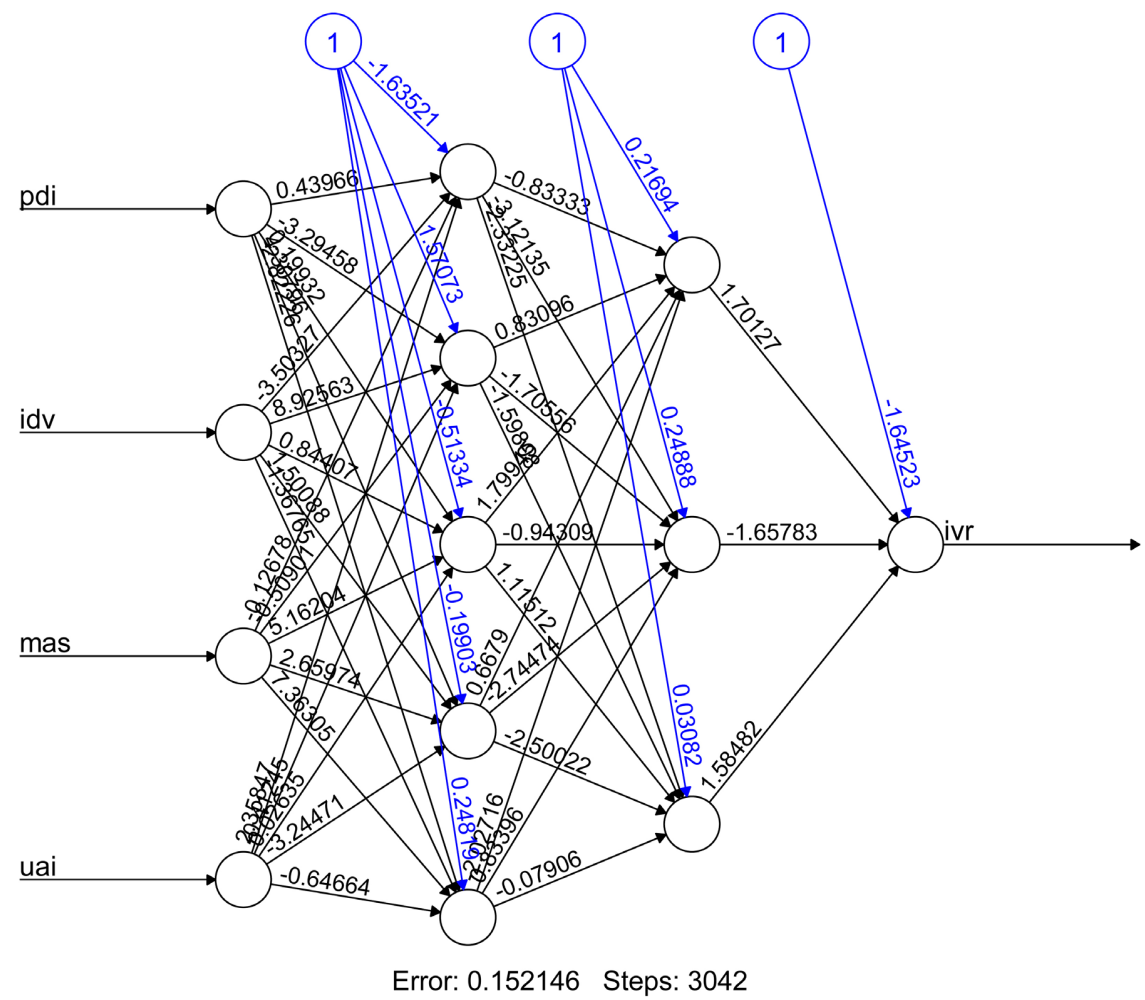

Figure A3. Neural network for modelling indulgence vs. Restraint based on the predictive factors.

To observe the performance of the used neural network, scatter plot of the predicted values of (IVR) versus the real (IVR) is plotted in Figure A4. It is clear that the points are close to the line with angle 45 degrees. Therefore, the predicts are satisfactory. 


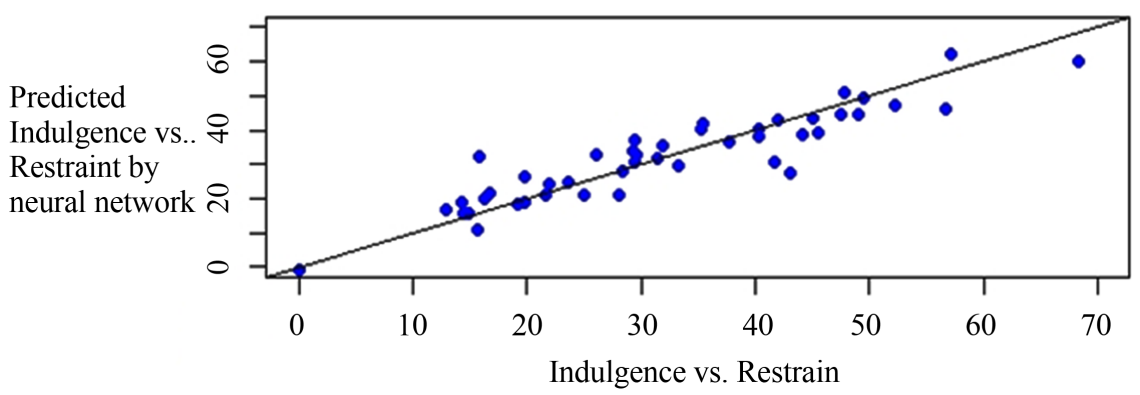

Figure A4. Scatter plot of the predicted values of (IVR) versus the real (IVR). 